\title{
DOS MODOS DE PRODUÇÃO DA MANUFATURA À UBERIZAÇÃO DOS PROCESSOS DE TRABALHO
}

\author{
http://dx.doi.org/10.21527/2176-6622.2020.53.79-90
}

Recebido em: 28/9/2019

Modificações solicitadas em: 20/1/2020

Aceito em: 26/2/2020

Cleiton Lixieski Sell

Doutorando em Direito pela Universidad de Burgos (UBU, Espanha). Mestrado em Direito pela Universidade Federal de Santa Maria (UFSM, Brasil). Graduação em Direito pela Universidade de Cruz Alta (Unicruz, Brasil). Integrante dos Grupos de Pesquisas Ordenación Territorial y Urbanística, Medio Ambiente y Desarrollo Sostenible (Orditer) da Universidad de Burgos e do Grupo de Pesquisa Direito e Fraternidade (GPDF) da Universidade Federal do Rio Grande do Sul (UFRGS). Pesquisador na área do Direito Ambiental e Direito do Trabalho. http://lattes.cnpq.br/4433295688074876. https://orcid.org/0000-0002-73241724. cleitonls.direito@gmail.com

\section{RESUMO}

A partir de um olhar sobre os avanços que a tecnologia trouxe no âmbito laboral e suas relações no meio ambiente, este estudo tem o objetivo de abordar a evolução dos processos de trabalho a partir da concepção da uberização no Direito do Trabalho. Com fundamento na teoria de base do materialismo histórico desenvolvido por Karl Marx, comprovou-se que a exploração da força de trabalho do homem tornou-se mais presente no século 21 , em que os avanços do sistema capitalista, por intermédio dessa mudança nos processos de trabalho, levam os trabalhadores à utilização de diversos meios informáticos. O método utilizado para o trabalho se consistiu no hipotético-dedutivo. Evidenciou-se que os processos de trabalho tornaram-se uberizados à medida que são operacionalizados em plataformas digitais e por determinado tempo. O uso dos instrumentos tecnológicos tornou-se imprescindível para grande parte dessas atividades; diferentemente, os reflexos recaem sobre a saúde dos trabalhadores pela concorrência e pela exigência por melhores resultados em termos de produção. Do mesmo modo, percebe-se que os processos de trabalho tornaram-se autônomos e autogestionados, modificando a estrutura tradicional de vínculo empregatício e de subordinação.

Palavras-chave: Relações de trabalho. Mecanização. Informatização. Uberização.

\section{FROM MANUFACTURING PRODUCTION MODES TO THE UBERIZATION OF WORK PROCESSES}

\section{ABSTRACT}

From a look at the advances that technology has brought in the work environment and its relations in the environment, this study aims to address the evolution of work processes from the conception of uberization in labor law. Based on the basic theory of historical materialism developed by Karl Marx, it was proved that the exploitation of man's labor force became more present in the 21st century, in which the advances of the capitalist system, through this change in work processes, lead workers to the use of various computer means. The method used for the work consisted of the hypothetical deductive. It became evident that work processes became uberized as they are operated on digital platforms and for a certain time. The use of technological instruments has become essential for most of these activities, in contrast, the reflections fall on the health of workers due to competition and the demand for better results in terms of production. Likewise, it is clear that work processes have become autonomous and self-managed, changing the traditional structure of employment and subordination.

Keywords: Work relationships. Mechanization. Informatization. Uberization.

\section{SUMÁRIO}

1 Introdução. 2 Meio ambiente e as relações de trabalho. 3 Processos de trabalho humano e os modos de produção. 4 A uberização dos processos de trabalho no século 21. 5 Reflexos da tecnologia de informação nas relações de trabalho. 6 Considerações finais. 7 Referências. 


\section{Debate}

\section{INTRODUÇÃO}

Este estudo possui dois propósitos em relação ao tema dos processos de trabalho humano e suas relações com o meio ambiente. O primeiro aspecto a ser destacado é o caminho que os processos de trabalho e os modos de produção percorreram da manufatura até o século 21 , uma vez que as modificações que ocorreram, e ainda ocorrerão, impactaram no resultado final das relações sociais. O segundo aspecto da investigação é referente à forma como a uberização foi inserida nas relações de trabalho, pois se trata de um fenômeno estruturado pelo uso de tecnologias e plataformas digitais que condizem com os períodos de transição moderno e pós-moderno.

Para compreender essa proposta ora abordada, deve ser analisado o período da Antiguidade greco-romana, em que as relações de trabalho, assim como as formas de comércio, eram realizadas exclusivamente pelo Mar Mediterrâneo. Nesse contexto histórico, o transporte marítimo era a única forma viável de realizar comércio com outras regiões mais distantes nas quais o surgimento do modo de produção utilizando mão de obra escrava foi o invento que impulsionou as atividades laborais (ANDERSON, 2000, p. 20-21). Cabe destacar - portanto - que as formas como os trabalhadores se tornaram escravos dependia de cada região, uma vez que ocorreu mais tarde na Ásia, que consistia em manter total controle sobre o trabalho e os modos de produção.

As transformações que ocorreram nos processos de trabalho durante o século 20 , no entanto, e a dinâmica de expansão do mercado levaram as relações do homem com a natureza para outros desafios e perspectivas no âmbito das relações laborais. Os sistemas de produção que consistiam na interação do homem com a natureza foram impulsionados de forma que a contribuição do homem foi a exploração da mão de obra, ao passo que na natureza se consistiu em fornecer terras (POLANYI, 2000, p. 162). Com as possibilidades da venda da força de trabalho e da venda das terras, o ser humano alinhou o útil ao agradável para desenvolver suas atividades de subsistência, bem como aperfeiçoando suas técnicas de trabalho.

Adentrando no aspecto das Tecnologias de Informação e Comunicação (TICs), os processos de trabalho foram revolucionados para o rompimento de paradigmas tradicionais, como locais fixos de trabalho nas quais empresas físicas foram substituídas por plataformas virtuais. Esse fenômeno é conhecido como a "googlelização do mundo" (VAIDHYANATHAN, 2011, p. 132), uma vez que a empresa Google se tornou o ambiente mais acessado do mundo em temos de busca de informação. O que na verdade interessa nesse aspecto é compreender o quanto a tecnologia modificou estruturas sólidas nas relações de trabalho em substituição de estruturas flexíveis e inovadoras em praticamente todos os processos de trabalho.

Sobre o tema dos processos de trabalho e as alterações nos modos de produção, destaca-se como o Direito acompanhou essas mudanças que refletiram nos âmbitos econômico, cultural, social e político. Do mesmo modo, as consequências que derivam desses câmbios implicam formas de comunicação humana por intermédio da informática, na qual desafiam novos riscos que podem expor direitos como a intimidade e a dignidade da pessoa humana (PÉREZ LUÑO, 2002, p. 118). Essa conjuntura que os meios tecnológicos trouxeram tornaram-se imprevisíveis e sofisticados na medida em que a demanda do mercado exige, uma vez que os trabalhadores se tornaram verdadeiros elos para impulsionar essa conectividade.

O estudo está estruturado metodologicamente em quatro partes, com a primeira consistindo em contextualizar o meio ambiente e as relações de trabalho. Após, será abordado o tema dos processos de trabalho e a interação dos modos de produção no sistema capitalista. Avançando esses tópicos, se aprofundará o tema do surgimento da uberização nas relações laborais no século 21, coadunando, especificamente, com o último aspecto do trabalho, que analisa os efeitos que a sociedade em rede, composta pelos meios tecnológicos, implicam nos atuais processos de trabalho.

\section{MEIO AMBIENTE E AS RELAÇÕES DE TRABALHO}

Nesse primeiro tópico que se refere ao estudo dos processos de trabalho e às formas de uberização no âmbito laboral, possui como premissa que as relações humanas na natureza são mediadas. Desse modo, as relações de trabalho ocuparam uma moldura na qual se tornaram mais flexíveis durante as jornadas de trabaIho, uma vez que contemplam dois ou mais empregos para garantir sua subsistência. Assim sendo, conceitos 
históricos como empregos tradicionais são vistos com mais volatilidade - ou seja - o trabalho temporário ou complementar à renda tornou-se a regra para grande parcela de trabalhadores. Em outras palavras, tornou-se a válvula de escape da informalidade diante da dura realidade do desemprego que assola todo o país.

O meio ambiente é composto por processos de trabalho que se tornam voluntários e involuntários, assim como visíveis ou invisíveis, mais intensos e menos intensos, assim como complexos ou simples. O que deve ser observado é que sem trabalho não existe vida humana na Terra e, por consequência, as relações de trabalho inexistiriam. Da mesma forma, percebe-se que o meio ambiente e as relações laborais possuem uma estreita relação, em que mesmo havendo as alterações nos processos de trabalho e a inserção de novas formas de trabalho, esse processo continua sendo a essência que compõe os elementos da organização da vida humana na Terra.

O século 20 foi cenário de um período que compreendeu o desaparecimento de modos de produção tradicionais, ferramentas e de engenhos que foram criados pelos mais simples trabalhadores. Nesse sentido, os efeitos que as mudanças políticas e econômicas proporcionaram afetaram a organização da classe trabalhadora na medida em que suas representações estavam sendo ameaçadas. Esse aspecto, igualmente, ocorreu com as condições de trabalho, que eram precárias, nas quais os trabalhadores adoeciam com graves problemas de saúde, assim como suas condições de vida financeira eram limitadas (ANTUNES, 2005, p. 123). Nesse cenário, os processos de trabalho tornaram-se objeto de exploração para o acúmulo de capital, bem como para reinventar novos modos de produção mais eficientes.

Com uma análise pontual sobre a situação da classe trabalhadora na Inglaterra, em pleno século 19, baseava-se no interesse privado e consistia em angariar novos métodos de acumular riqueza. Nesse período "[...] a relação entre o industrial e o operário não é uma relação humana: é uma relação puramente econômica - o industrial é o capital, o operário é o trabalho" (ENGELS, 2010, p. 308). Essa relação de trabalho tornou-se o carro-chefe do sistema capitalista, uma vez que o homem transformou-se em objeto de exploração pelo próprio homem, na medida em que a obsessão em adquirir bens e dinheiro tornou-se seu objetivo em detrimento da compra de força de trabalho.

Analisando o contexto histórico, as submissões das condutas humanas aos regramentos jurídicos na natureza determinam o quão possam ser variáveis e se alterar na medida em que um fenômeno social ou econômico é composto. As relações humanas são moduladas pela interação de comando que o empregador possui sobre seus empregados (comandados), bem como pelo controle da ação (trabalho) a que está sujeito o empregado. Esse sistema, portanto, constituído há muito tempo, possui o objetivo de troca do esforço físico pelo valor monetário. A venda de trabalho humano, no entanto, é precedida por uma relação que para Marx foi um dos mais conflituosos temas do século 18, pois "[...] por venda de uso entendemos a troca de funções corpóreas por moeda, que seja baseada na igualdade jurídica (teórica) entre os contraentes e que seja revogável" (BERLINGUER; GARRAFA, 2001, p. 64).

Nos dois últimos séculos, as relações de trabalho sofreram diversas alterações com o uso das tecnologias, quando os sofrimentos com as rústicas ferramentas utilizadas foram atenuados por meios práticos e menos desgastantes do esforço físico dos trabalhadores. Do mesmo modo, as tarefas árduas nas fábricas submetidas aos efeitos de temperatura e de movimentos repetitivos foram substituídas pela informatização das operações de trabalho (DEJOURS, 2007, p. 27). Esse período marcou o quão dura foi a vida de um trabalhador que cumpria mais de dez horas de trabalho diárias, bem como era auxiliado por todos os integrantes da família, em que havia mínimas medidas de segurança ou Medicina do Trabalho que prevenisse qualquer acidente.

Os processos de trabalho foram afetados pela precarização, terceirização e, não apenas isso, pela uberização nesse início de século 21. Diante dessa realidade, cabe revisitar o fenômeno do neoliberalismo associada à tendência da terceirização nos processos de trabalho, pois produziram efeitos maléficos na atividade laborativa em termos de exploração da força de trabalho. Essas articulações nos modos de produção possuem raízes no taylorismo e no fordismo, as quais permaneceram mescladas na atual conjuntura das relações de trabalho (ANTUNES, 2018, p. 120).

Esse cenário ocorreu, especificamente, com a inserção das novas formas que os processos de trabalho desenharam, refletindo distintas maneiras de intensificação e flexibilização das jornadas laborais. Do mesmo modo, a informalização dos contratos de trabalho ganhou espaço na medida em que a legislação protetora dos direitos dos trabalhadores foi sendo encurtada. Diante dessa nova tendência e por intermédio dos meios 
tecnológicos nas relações de trabalho, as atividades mecanizadas e informatizadas ocuparam um espaço sem retorno, em que somente ocorre avanço rumo ao descobrimento de ferramentas mais eficientes e eficazes como pressuposto financeiro.

Essa profunda transformação nas relações de trabalho retratam o sentido que a precarização desses processos trouxe, bem como pelo fato de que as estruturas políticas e econômicas impactaram nas garantias jurídicas da classe trabalhadora. Nesse contexto, as reestruturações que as formas de trabalho ocuparam, como é o caso da uberização, constituem-se de elementos que contribuem nas mudanças que os processos de trabalho tradicionais sofreram em direção à era do trabalho digital, na qual trabalhadores são vigiados por máquina, e sua produção é medida por dados estatísticos de forma instantânea durante as jornadas de trabalho.

\section{PROCESSOS DE TRABALHO HUMANO E OS MODOS DE PRODUÇÃO}

Nos processos de trabalho, assim como nos modos de produção, são formas que o ser humano adapta constantemente aos novos contextos das relações humanas. O âmbito da filosofia estuda o ser humano a partir de sua função na natureza, e que de uma forma ampla e sem maiores classificações, pode ser entendida como uma antropologia (GOLDMANN, 1979, p. 7). Em outra lente de análise, o pensamento dialético que consiste nos fatos empíricos é abstrato na medida em que não se concretizarem no campo prático, assim como o pensamento formado sobre os processos de trabalho pode ser considerado um aspecto parcial de uma realidade em análise - no entanto - pertence a um grupo social, que é constituído pelas relações que exercem no contexto histórico.

No tema dos processos de trabalho, o período que compreende a segunda metade do século 17 até praticamente meados do século 18 , o comércio e a navegação eram os dois grandes objetos de exploração da força de trabalho, uma vez que a manufatura caminhava a passos lentos até sua expansão nas colônias (MARX, 2011, p. 127). As leis que surgiam tinham a finalidade de alinhavar os esforços dos navegantes em direção à expansão dos produtos para outros continentes, na qual figurava a Inglaterra como o país com maior expansão marítima. Por outro lado, a manufatura aos poucos foi submetida às tarifas do mercado interno, impactando no âmbito internacional no qual havia impostos para manutenção das atividades.

Já na segunda metade do século 19, Frederick Winslow Taylor foi um dos grandes expoentes científicos da época com a criação do conhecido "Sistema Taylor", revolucionando as formas de análise dos processos de trabalho. Esse descobrimento teve o objetivo de eliminar o tempo de trabalho de uma operação para outra, que na verdade significa controlar cada atividade executada pelo trabalhador (PINTO, 2010, p. 26). À medida que a preocupação com os processos de trabalho se tornava mais intensa e degradante, a força de trabalho do homem era a única forma que o capitalista tinha para melhorar seu rendimento sobre os operários da fábrica.

Essas experiências dos trabalhadores nos processos refletem as formas como o homem se relacionou com a natureza, bem como a utilização das Ciências Naturais no estudo de instrumentos empíricos sobre a veridicidade dos fatos que ocorrem nas relações sociais. Em relação aos modos de produção, os seres humanos convivem em constantes conflitos com a natureza, e em se tratando do ordenamento jurídico, possuem um dos mais antigos métodos para resolução desses conflitos em distintas áreas que envolvem interesses opostos (REDORTA, 2009, p. 33-34).

Diante desse cenário, os processos de trabalho e os modos de produção foram intensificados na medida em que o sistema capitalista se reinventou no aspecto da exploração do trabalho. $O$ efeito que essa intensificação ocasiona na vida dos trabalhadores vai muito além do desgaste físico e psíquico, uma vez que provoca o surgimento de acidentes e doenças de trabalho por exaustão das jornadas laborais (ROSSO, 2007, p. 193-194). A consequência desses métodos sobre os processos de trabalhado resultou em um rumo perverso em termos de direitos sociais, na qual ocuparam constantes discussões no campo econômico na medida em que o objetivo é aumentar o rendimento na produção.

O prolongamento das jornadas de trabalho já foi objeto de pesquisa de Karl Marx, em meados do século 19. O autor compreendeu que a maquinaria se tornava a forma mais útil de incrementar força na produtividade do trabalho. Dessa mesma forma, a utilização da máquina encurtava o tempo de trabalho necessário para a produção das mercadorias, bem como se tornava o método mais poderoso para que o trabalhador prolongasse as jornadas de trabalho que anteriormente realizava manualmente (MARX, 2013, p. 475-476). Diante 
dessa nova artimanha criada para aumentar a exploração de trabalho do homem, a maquinaria começou a ser utilizada em todas as etapas de produção, assim como o interesse em substituir as máquinas danificadas pelo tempo de uso ou por alguma avaria que as impedia de funcionar corretamente.

Aprofundando essa questão, o trabalho humano forma capital, que na realidade é o trabalho objetivado que Marx sustentava em sua tese. De modo diferente, quando o trabalho passou a ser constituído pelo contrato de trabalho assalariado, o ser humano pressupõe o capital como objetivo à medida que vende sua força de trabalho em troca de moeda (dinheiro). Desse modo, o trabalhador consegue comprar mercadorias para seu sustento e consome riqueza, no entanto não pode apropriar-se dela (DUSSEL, 2012, p. 144-145). 0 trabaIho na perspectiva dos modos de produção foi subsumido pela busca do capital pelo próprio capital, uma vez que o trabalhador se tornou o elemento imprescindível no processo.

Avançando no próximo tópico, compreende-se que o homem fez surgir distintas formas de trabalho que compreendem todas as evoluções científicas e tecnológicas em termos de ferramentas e métodos. Entre essas mudanças, surgem meios de trabalhos virtuais, bem como as formas de relacionar com os indivíduos que se deslocavam até uma reunião com os amigos vindo a se tornar-se um encontro digital (LÉVY, 2001, p. 187). Sendo mais claro, a tecnologia tornou-se independente na medida em que o ser humano está utilizando esses meios como forma de aprofundar as pesquisas científicas em busca de desenvolver métodos mais produtivos. Não obstante todos esses aspectos abordados e que contemplam principalmente os dois últimos séculos, a História escreve e escreverá novos capítulos sobre essas tendências, em que os desafios se tornam constantemente novos desafios no âmbito das relações de trabalho.

\section{A UBERIZAÇÃO DOS PROCESSOS DE TRABALHO NO SÉCULO 21}

Após realizar um recorte e ao mesmo tempo um resgate sobre os elementos que caracterizaram os processos de trabalho da manufatura e da mecanização, será realizada uma abordagem sobre os direitos sociais vigentes, bem como um panorama sobre os antecedentes a partir do período pré-Revolução Industrial até o século 21, em que surgiu o fenômeno da uberização. Iniciando pela Constituição da República Federativa do Brasil de 1988 (CRFB/1988), o presente dispositivo trouxe um capítulo específico sobre os direitos sociais aos cidadãos brasileiros. Do mesmo modo, a Consolidação das Leis do Trabalho (CLT), editada pelo Decreto-Lei no 5.452/43 (BRASIL, 1943), que posteriormente, em 2017, sofreu alterações pela Lei no 13.467/17 (BRASIL, 2017), contemplou em forma de código específico esses direitos. Esses textos de lei reforçam a importância que esse tema possui em relação à garantia do bem-estar social e da dignidade da pessoa humana nas relações laborais.

No tema do fenômeno da uberização, está se tornando rotineiro nos processos de trabalho o não reconhecimento do vínculo empregatício de trabalhadores, uma vez que esse aspecto foi impulsionado com a publicação da Lei no 13.352/16 (BRASIL, 2016), também conhecida usualmente como a lei "Salão Parceiro". Esse dispositivo trouxe a novidade da desobrigação de proprietários de salões de beleza a reconhecer os vínculos dos trabalhadores da empresa, que assim passam a ser autônomos nas atividades de manicures, pedicures, cabeleireiros, esteticistas e demais funções de um salão de beleza. Em resumo, aquele(a) cabeleireiro(a) ou maquiador(a), que trabalha um período em um local de trabalho durante a semana, pode ser considerado um(a) prestador(a) de serviços do salão de beleza sem vínculo trabalhista com seu empregador.

A uberização dos processos de trabalho compreende como as novas formas de trabalho tornaram-se essencialmente constituídas por meios eletrônicos. Desse modo, essas mudanças proporcionaram novos desafios a serem superados pelos trabalhadores, bem como contemplam novas formas de tutela jurídica dos empregados - em outras palavras - essas modalidades de trabalho refletem nas profundas alterações nos processos e nos ambientes de trabalho. A partir da utilização das novas tendências que as relações de trabaIho tomaram, cresce a possibilidade de a uberização dos processos de trabalho se ampliar, uma vez que surgem formas de trabalho fragmentadas, ou seja, o aumento de trabalhadores para realizar tarefas em período parcial.

Para aprofundar a discussão no âmbito das relações de trabalho, recorre-se a um dos primeiros pensadores modernos, como Karl Marx. O autor analisa que suas contradições estudadas sobre a modernidade fizeram enxergar que a busca de respostas para tantas perguntas deve voltar-se para o próprio período da modernidade (BERMAN, 1986, p. 146-147). Para compreender essas mudanças nos processos de trabalho do 
século 19, analisando até esse início de século 21, faz-se necessário compreender esses câmbios provocados pelos avanços tecnológicos e reduzidos aos instrumentos de trabalho, bem como relacionar essas modificações na vida dos seres humanos. Uma dessas mudanças é a utilização das plataformas digitais com aplicativo Uber, que pode ser instalado nos smartphones como nova forma de trabalho, uma vez que

[...] nasce do casamento entre um aplicativo móvel (App) e motoristas de limusines, cujos serviços eram pagos pelos clientes por cartão de crédito. Em seguida, expandiu a atuação ao agregar motoristas não profissionais de carros de luxo, passando de 10 mil carros em 2013 para 150 mil em dois anos, com atuação em 83 países e 632 cidades (VENCO, 2019, p. 4).

O Uber é um exemplo de como o sistema capitalista impulsionado pelos meios tecnológicos provocou uma verdadeira mudança em relação aos contratos formais de trabalhadores, uma vez que era previsto claramente um objeto específico de trabalho e sua forma de realização. Em relação aos motoristas de Uber, estes "[...] permanecem proprietários dos meios diretos de produção, mas sua atividade é subordinada diretamente ao capital sem mediação de relação empregatícia" (FONTES, 2017, p. 62). Esse processo de trabalho da uberização tornou-se uma forma alternada de exploração da força de trabalho do ser humano, em que os modos de produção se retroalimentaram dessas novas formas de trabalho, na qual a saúde dos trabalhadores é deixada de lado devido à exigência e sistematização com que o sistema se mantém.

Nesse início de século 21 percebe-se uma mudança significativa nas formas de trabalho e nos métodos de realização dos contratos de trabalho em diversos setores econômicos. Um exemplo dessa nova roupagem são as tarefas por demanda que surgiram e que compreendem os motoristas de passageiros por intermédio de aplicativos e utilização de Internet. Do mesmo modo, os setores de serviços que compreendem a maior parte dos trabalhadores sofreram uma forte tendência no trabalho autônomo, o que implica mais tempo de trabalho para manter sua subsistência familiar (ALMEIDA, 2018). Nesse atual e incerto cenário laboral, o mundo da tecnologia está avançando no âmbito dos processos de trabalho, e caberá ao trabalhador encarar as novas demandas desses processos de trabalho.

Ainda no contexto da uberização da classe trabalhadora, a partir de uma análise mais específica sobre a Reforma Trabalhista, identifica-se que são dois aspectos principais que esta lei se propõe em relação aos direitos sociais dos trabalhadores brasileiros. Em um primeiro momento identifica-se que o objetivo é diminuir a proteção estatal sobre os trabalhadores, ao passo que em segundo plano é deixar mais clara as formas de negociação das relações de trabalho (LIMA; LIMA, 2017, p. 9). O que em realidade esse dispositivo jurídico trouxe diz respeito a um viés, sobretudo patronal, pois no conjunto dos direitos sociais dos trabalhadores, esses direitos tornaram-se mais pressionados em termos de realização de acordos ou negociações coletivas, e em certa medida, enfraquecendo o apoio dos sindicatos trabalhistas.

No atual cenário da uberização de diversos processos de trabalho, percebe-se que os conflitos jurídicos ocorrem inclusive entre os trabalhadores, como é o caso dos trabalhadores imigrantes com os nacionais, em que o território ocupado por ambos torna-se um espaço de disputa para o mercado. Nessa linha de raciocínio, as formas de trabalho também se classificam ou se distinguem entre os trabalhadores brancos e negros, dos qualificados dos que não o são, dos trabalhadores experientes dos que estão entrando no mercado de trabalho pela primeira vez, entre outros tantos exemplos que realizam um recorte categórico (ANTUNES, 2005, p. 31).

Diante dessas observações, evidencia-se que as relações de trabalho sofreram diversas interferências em termos de previsão legal, e uma das mais emblemáticas diz respeito às formas de flexibilização das horas laborais. Os próprios sindicatos de trabalhadores já não conseguem combater essa realidade à qual os trabaIhadores são submetidos no que se refere ao prolongamento das jornadas de trabalho. Do mesmo modo, essa tendência ocorre com a intensificação que se tornou mais presente do que nunca no século 21 (ROSSO, 2017, p. 265-266). O fato é que, para manutenção do perverso sistema econômico, há uma necessidade premente de restabelecer novas formas de exploração de trabalho humano em que os direitos sociais são suprimidos ou negociados informalmente entre empregador e empregado.

No contexto da flexibilização e da intensificação, nem as tecnologias, nem as alterações políticas e econômicas e tampouco as mudanças jurídicas puderam bloquear a forte onda que o sistema criou e continua restabelecendo como alternativa para fortalecer suas bases. A partir dessa perspectiva sobre os processos de trabalho, "[...] as forças produtivas sociais disponíveis, bloqueadas pela propriedade privada, só poderiam se desenvolver como forças produtivas do capital contra o trabalho, ou seja, como forças destrutivas" (ARCARY, 
2013, p. 411). Essa visão remete a um prognóstico sem uma perspectiva de alterações em sua estrutura, pelo menos em curto ou médio prazo, uma vez que as lutas sociais se tornaram reféns da classe dominante e consequentemente provocam baixas perspectivas de alterações em termos de mudanças nas formas de proteção do trabalhador.

A perspectiva da uberização fez com que os processos de trabalho fossem reconfigurados para a era digital da informação - ou seja - o homem não necessita buscar informações em bancas de jornal ou locais físicos privados ou públicos de informações, uma vez que se encontram disponíveis e chegam ao interessado pela Internet em uma velocidade incomparável com qualquer outro meio de comunicação (KUMAR, 2006, p. 49-50). Do mesmo modo, as atividades laborais se modelaram para essa mudança na medida em que consistem em utilizar aplicativos digitais em smartphones como ferramenta de trabalho. Por outro lado, essa mesma sociedade pós-industrial vivenciou um abismo cultural em termos de adaptação a esses meios tecnológicos, nos quais as relações de trabalho se tornaram conectadas virtualmente, observando-se que não é possível realizarem certos trabalhos sem que os trabalhadores se adaptem às plataformas digitais.

Não apenas o uso de aplicativos digitais como o Uber, mas, também, o uso das tecnologias tem proporcionado múltiplas discussões em áreas dos direitos de privacidade dos trabalhadores diante das novas formas que se estenderam aos processos de trabalho. Nesse mesmo fio condutor, outros direitos fundamentais tornaram-se objetos de enfrentamento em relação às possibilidades que surgiram com a era da informatização, em que no âmbito jurídico as tensões sobre a tutela do direito de privacidade tornaram-se presentes nas ações judiciais nos dois últimos séculos, bem como as formas de processar as informações via Internet (LEONARDI, 2012, p. 373). O tema que envolve essa questão de proteção dos direitos fundamentais ganhou uma importância urgente sob o ponto de vista jurídico, uma vez que esses direitos tornaram-se objetos de manutenção e garantia de defesa dos direitos humanos em acordos internacionais.

É incontroverso, ademais, que no atual cenário em que se encontram os processos de trabalho alinhados com as novas tecnologias, as formas de trabalho informal aumentaram consideravelmente, assim como o surgimento de novas demandas jurídicas em relação a esses novos trabalhos. O que interessa é perceber o desabrigo que ocorre em relação ao vínculo obrigacional e de segurança aos quais os trabalhadores de aplicativos como o Uber, Cabify e outros aplicativos estão sujeitos, posto que, na maioria das vezes, o trabalhador motorista está percorrendo um itinerário ou lugar que não conhece e tampouco há garantia de segurança em termos de estabilidade de rendimento monetário.

De tudo que foi abordado sobre essa onda da uberização dos processos de trabalho, resta, concluso, que esse tipo de trabalho temporário é reconhecido como uma forma de complemento ou atividade principal de renda para grande parcela dos(as) trabalhadores(as). Esse exemplo utilizado no estudo sobre a uberização por meio de plataformas digitais representa uma forma alternativa de relações de trabalho e sem um estatuto específico, em que o trabalhador opera a partir de sua disponibilidade e de seus meios de trabalho como o carro e um smartphone para realizar sua atividade. Por outro lado, os trabalhadores estão sujeitos a questões de segurança, estabilidade jurídica e financeira, ao tempo que intrinsecamente possuem gastos externos (alheios), como a manutenção de uso do automóvel e seguro contra possíveis danos.

\section{REFLEXOS DA TECNOLOGIA DE INFORMAÇÃO NAS RELAÇÕES DE TRABALHO}

A utilização das tecnologias nos processos de trabalho é algo que se tornou irreversível por diversos motivos, como comunicação eficiente, aumento da produção, praticidade, flexibilidade, utilização de melhores técnicas, entre outros. Desse modo, essa realidade não se torna mais uma opção por parte dos empresários, uma vez que se tornou imposição para produção e circulação de bens (GRASSELLI, 2010, p. 113). Diferentemente, essas mudanças nas relações sociais, que foram provocadas com os instrumentos informáticos, refletem na vida das crianças e dos jovens, que já nascem inseridos na sociedade da informação, uma vez que lhes é introduzida e estimulada por meios virtuais a aquisição de tecnologias disponíveis no mercado de produtos.

Para analisar essas mudanças que ocorreram nas relações laborais, faz-se necessário entender que toda mudança ou, como Jean Lojkine define como "Revolução Informacional”, perpassa, obrigatoriamente, por riscos e ambiguidades durante e após a utilização dos instrumentos tecnológicos (2002, p. 308-309). Com base nessa perspectiva, as relações como a produção e circulação de mercadorias tornaram-se flexíveis e com múltiplas possibilidades de realização de transações, em que o ambiente de trabalho, que estava definido fisica- 
mente em uma sala ou conteiner, aos poucos se tornou volátil de um país para outro por intermédio de uma tela. Essa lógica proposta pela tecnologia cria perguntas com respostas frágeis, bem como questionamentos nos âmbitos jurídico e econômico, uma vez que se tornam objetos de intensos confrontos para garantia dos direitos dos indivíduos.

A comunicação virtual tornou-se a forma essencial de relacionamento dos seres humanos com a sociedade e com a atividade laboral. Houve, nas formas comunicativas de informação, extraordinárias mudanças que desaguaram nos processos de trabalho com novas demandas no mercado consumidor (CASTELLS, 2003, p. 225). Essas mudanças que ocorreram e continuam a ocorrer, alteraram até mesmo perspectivas sobre a vida humana, na qual os momentos de felicidade e lazer estão se resumindo em encontros virtuais ou como os transportadores de alimentos ou cargas em rodovias se tornaram controlados (monitorados) por aplicativos (tecnologias) de outros países. O que importa analisar é que essas mudanças revolucionaram as formas como os processos de trabalho são realizados, havendo a necessidade de um reaprendizado das ferramentas dos processos de trabalho tradicionais que eram desenvolvidos pelas empresas.

Essas mudanças se tornaram-se tão intensas que a privacidade dos trabalhadores no local de trabalho se tornou objeto de análise e previsão jurídica no âmbito laboral. Nesse aspecto, a influência dos meios informáticos impulsionou uma preocupação com relação à proteção de dados pessoais dos trabalhadores na medida em que se utilizou de meios de vigilância dos locais de trabalho. Com a aprovação do Código do Trabalho por intermédio da Lei no 99/2003 (BRASIL, 2003), uma série de restrições foi prevista em relação à proteção dos dados pessoais dos trabalhadores como: informações relativas à vida privada, exceto as indispensáveis para aptidão do trabalho; o empregador não pode exigir informações sobre a saúde ou gravidez, salvo quando necessárias em relação à especificidade da função ; informações médicas só podem ser transmitidas do médico para o empregador em relação ao aspecto de estar ou não apto para o trabalho; deve haver por parte do empregador a proteção das informações pessoais de seus empregados; a utilização de vigilância do local de trabalho e do trabalhador a distância deve ser realizada desde que seja com o objetivo de sua segurança e proteção. Esse aspecto também contempla os equipamentos ou estabelecimentos do empregador (GARCIA; MARTINS, 2006, p. 374-375).

Voltando à questão do direito à privacidade e proteção de dados pessoais, estes direitos tornaram-se fundamentais para manutenção e garantia de princípios como da dignidade da pessoa humana. Nesse sentido, essa abordagem caracteriza dois elementos que fazem parte da compreensão desses direitos, "[...] de que nossa tarefa falhará caso não leve em consideração o direito como um fenômeno que somente atinge sua plena realização após ser aplicada à realidade da arquitetura social; [...] tal realidade em boa parte acondicionada pelo desenvolvimento tecnológico" (DONEDA, 2006, p. 33). Diante dessas questões, o desenvolvimento tecnológico demanda o comprometimento de regulação jurídica (tutela), uma vez que cada mudança que um portal eletrônico sofre necessitará de proteção de dados pessoais dos trabalhadores, do mesmo modo que demandará novos aspectos científicos para formação e capacitação desses operadores.

Durante todo o século 20 o capitalismo industrial era a fonte primordial de desenvolvimento econômico dos indivíduos, posto que o capital girava em torno da ampliação das indústrias e dos mercados de produção em massa. Essa realidade foi tomando outro sentido com a influência das redes de comunicação e das alterações que os processos de trabalho sofreram na era da informação e comunicação (RIFKIN, 2001, p. 111-112). Nesse período se discutiu o desenvolvimento do acesso e do poder que a comunicação exerce sobre a sociedade, e a partir de uma nova forma de desenvolvimento econômico não há mais limites de território entre países em termos de informação, bem como os objetos que eram fabricados com maior solidez e durabilidade já se transformaram em menos resistentes e com a necessidade de adaptar novos componentes para que se possam tornar úteis e com maior capacidade de resistência.

No contexto das relações de trabalho, o capitalismo industrial no período pré-revolução e pós-revolução, sofreu notáveis modificações, uma vez que em meados de 1960, o foco central das empresas capitalistas se consistia em acumular capital para injetar mais capital no mesmo negócio (DUPAS, 2000, p. 29-30). Um pouco mais à frente, no período em que o fordismo esteve no auge, em pouco tempo foi deixando a grande produção de lado, observando-se um panorama histórico após a Segunda Guerra Mundial, em que os países mais industrializados somaram esforços rumo à produção em linhas de montagem, em que a competição entre as melhores tecnologias para produção se tornava regra em todos os países que tinham capital financeiro para pagar. 
Os reflexos que a tecnologia trouxe para sociedade da informação remetem a conceitos como a teoria do "Poder da Comunicação", de autoria de Manuel Castells, na qual aborda como os meios tecnológicos se tornaram ferramentas para obter poder. Do mesmo modo, a estrutura do tempo que foi desenvolvida pelo taylorismo continua a mesma em relação aos trabalhadores (CASTELLS, 2013, p. 89-90). Com a intensa luta política e econômica no âmbito dos direitos sociais, a tecnologia tornou-se objeto de controle da sociedade; por outro lado, está vinculada ao desenvolvimento econômico, uma vez que a produção de mercadorias tornou-se mais produtiva devido aos avanços que a ciência proporciona em termos de melhoramento genético.

Na sociedade moderna composta pelas relações de trabalho, o uso das tecnologias se tornou necessário sob pena de o indivíduo se tornar excluído à medida que a estrutura do poder ganhou novas tendências que se organizaram no mercado. Nessa ótica de análise, torna-se "[...] imprescindível que a relação entre as novas tecnologias, os direitos da personalidade e os poderes de mando e gestão do empregador seja permeada pelo equilíbrio, com o apoio nos princípios da dignidade, razoabilidade e da proporcionalidade, dentre outros, [...]" (GRASSELLI, 2011, p. 85). Cabe observar, todavia, que os meios informáticos disponibilizados pelo empregador são suscetíveis à tutela, que significa dizer que devem obedecer aos direitos fundamentais como privacidade e intimidade, assim como vinculados a outros princípios contemplados pela Constituição.

O uso das tecnologias tornou-se uma aposta política e econômica na sociedade formada por redes, que a partir da perspectiva lógica econômica, para a qual o mercado é direcionado, o mercado laboral seguiu uma tendência diretora que pode ser descrita em três grandes visões. Ei-las “[...] 1) O princípio nacional é deslocado pelo princípio global; 2) a lógica da informação desloca a lógica industrial e 3) a lógica do cultural desloca a lógica do social” ${ }^{11}$ (LASCH, 2005, p. 59). Essas perspectivas avançaram no âmbito social, econômico, político, jurídico, ambiental, entre outros ramos, no entanto o aspecto em que ocorrem se torna universal, ou seja, se houver uma crise econômica em um país de grande potência mundial, como são os casos dos EUA ou da China, os efeitos se refletem em outros países, inclusive o Brasil.

De tudo que foi abordado sobre as tendências laborais do século 21 , o direito da informação tornou-se um novo ramo de pesquisa e trabalho no âmbito jurídico. Esses novos desafios que tiveram início em meados dos anos 70 do século passado, quando os meios informáticos já existiam e já possuíam ferramentas sofisticadas, levaram ao surgimento de problemas como a regulação jurídica (GONÇALVEZ, 2003, p. 19-20). O que é interessante analisar nesse ponto é o quanto essas mudanças refletem nas relações laborais, ou observar que a regulação jurídica se tornou o grande desafio que os meios tecnológicos proporcionaram. Cumpre destacar, portanto, que a uberização dos processos de trabalho teve origem dos países mais desenvolvidos e que em pouco tempo expandiram essa tecnologia para todos os países em proporções distintas.

Os meios informáticos foram criados para auxiliar as atividades do homem na sociedade, compreendendo os meios de comunicação e as ferramentas para o trabalho. Complementando essa informação, no século 17 um estudioso chamado John Napier já desenvolvia mecanismos como os "Ossos de Napier" para decifrar operações matemáticas complexas (PINHEIRO, 2013, p. 59). Desse modo, os cálculos matemáticos foram responsáveis por desenvolver as tecnologias informáticas que vigoram até os dias de hoje, uma vez que os programas de Internet que são instalados nos microcomputadores ou smartphones são a prova viva de quanto a capacidade de criação do homem se tornou realidade, do mesmo modo que as ferramentas se fazem tão necessárias e podem ser utilizadas como meios de trabalho, como é o caso desses aplicativos.

O direito à garantia da privacidade do indivíduo tornou-se objeto de conflitos jurídicos laborais na medida em que esses direitos foram ficando mais complexos. Mantendo essa linha de pensamento, são incontáveis as ocasiões em que conflitos sobre direitos fundamentais tornam-se elementos que reforçam a tese de que, se por um lado as tecnologias proporcionaram uma ampliação dos processos de trabalho e dos modos de produção, por outro inseriram mais atenção em relação à garantia das informações pessoais que são disponibilizadas em meios tecnológicos (NISSENBAUM, 2011, p. 231). Essa proteção de dados pessoais revelou-se imprescindível para a proteção dos direitos do indivíduo, uma vez que os instrumentos tecnológicos podem ser utilizados para o bem ou para o mal, e cabe ao ser humano, que ao fim e ao cabo os criou, garantir a tutela jurídica dessas novas ferramentas de trabalho.

\footnotetext{
Idioma original. "1) El princípio de lo nacional es desplazado por el princípio de lo global; 2) la lógica de la información desplaza la lógica industrial, y 3) la lógica de lo cultural desplaza la lógica de lo social”.
} 


\section{Direito自

\section{CONSIDERAÇÕES FINAIS}

O presente estudo abordou as alterações que ocorreram (e ainda ocorrerão) com os processos de trabaIho desde o período da manufatura, perpassando pela Revolução Industrial, até as novas formas de trabalho que surgiram até o século 21. Para que fosse possível demonstrar com elementos essas alterações sofridas, o foco foi direcionado em desvelar a medida com que os processos de trabalho se tornaram uberizados - ou seja - os trabalhadores procuram trabalhos temporários ou por jornadas com a utilização dos meios informáticos. Restou comprovado que a tecnologia influenciou na ampliação e remodelação das formas de trabalho que ficaram mais claras com o aumento do uso de plataformas digitais, como é o caso dos trabalhadores que utilizam aplicativos de transporte.

No aspecto da mecanização e da revolução informacional, os processos de trabalho tornaram-se dependentes desses meios. Do mesmo modo, os trabalhadores são cada vez mais exigidos para desenvolver atividades produtivas e competitivas em âmbito nacional e internacional. Com análise sobre os meios tecnológicos, é incontestável que abrem portas para novas formas de trabalho, entretanto fecham outras para trabalhadores que não possuem o acesso e/ou conhecimento sobre esses instrumentos. Mesmo não sendo objetos deste estudo, mas que estão intrinsecamente relacionados ao tema, esses novos modelos de trabalho têm afetado a saúde dos trabalhadores na medida em que não conseguem se desconectar do trabalho, o que já é uma realidade em diversas atividades, cujo objetivo é manter o ser humano ocupado produzindo além das expectativas e em sua casa para grupos empresariais.

A perspectiva que o neoliberalismo propõe no discurso de uma economia voltada para o desenvolvimento de um país ultrapassa a forma como a modernização impactou nos processos de trabalho, pois o atual sistema está livre para explorar a força de trabalho do ser humano. Assim como a uberização é um tema que ganhou destaque nos meios de comunicação sociais, trata-se de um reflexo da criação de uma rede de trabaIhadores autônomos, que em outro modo de dizer são aqueles que se autogestionam no trabalho sem haver um vínculo empregatício em curto ou médio prazos.

Essas novas formas de trabalho deixam obsoletas tendências como o emprego tradicional, no qual o operário vai à fábrica, cumpre sua jornada de trabalho e volta para casa para descansar. Outro aspecto relevante é a flexibilidade com que a uberização impacta nos horários, uma vez que podem ser diversificados por atividade ou meta alcançada durante a jornada laboral. Restou evidenciado que a uberização dos processos de trabalho é a projeção que o sistema capitalista (inteiramente econômico) ressurgiu em forma de agressividade nas relações de exploração da força de trabalho deste século.

Nessa perspectiva, a instabilidade do trabalho assusta milhões de trabalhadores e trabalhadoras de todo o Brasil, e porque não dizer do mundo, em que o trabalho parcial ou por plataformas digitais tornou-se uma nova e desafiadora forma de trabalho. Do mesmo modo, esse crescimento da utilização de plataformas on-line contribuiu para o aumento do número de indivíduos que se tornaram microempreendedores individuais, ao passo que surgem outras plataformas de setores econômicos como o Airbnb, que é um aplicativo para locar imóveis ou partes de imóveis pessoais para outros indivíduos como se fosse um serviço de hotelaria. Esse é mais um exemplo do quanto o uso de tecnologias se tornou frequente na sociedade em que acesso à informação, adaptabilidade e criatividade se tornaram competências imprescindíveis para os trabalhadores.

\section{REFERÊNCIAS}

ALMEIDA, C. A uberização do trabalho no século XXI. Tarefas sob demanda ganham espaço em um mercado transformado pela automação e pela inteligência artificial. In: Época, ago./2018. Disponível em: https://epoca.globo.com/tecnologia/noticia/2018/05/uberizacao-do-trabalho-no-seculo-xxi.html. Acesso em: 24 jan. 2020.

ANDERSON, P. Passagens da antiguidade ao feudalismo. Tradução Beatriz Sidou. São Paulo: Brasiliense, 2000.

ANTUNES, R. O caracol e sua concha: ensaio sobre a nova morfologia do trabalho. São Paulo: Boitempo, 2005.

ANTUNES, R. O privilégio da servidão. O novo proletariado de serviços na era digital. São Paulo: Boitempo, 2018.

ARCARY, V. Uma etapa histórica de reformas ameaçadas: limites da regulação na época do capitalismo decadente. In: NAVARRO, Vera Lúcia; LOURENÇO, Edvânia Ângela de Souza (org.). Avesso do trabalho III: Saúde do trabalhador e questões contemporâneas. São Paulo: Outras Expressões, 2013.

BERLINGUER, G.; GARRAFA, V. O mercado humano. 2. ed. Brasília: Universidade de Brasília, 2001. 
BERMAN, M. Tudo que é sólido desmancha no ar: a aventura da modernidade. 2. ed. São Paulo: Companhia das Letras, 1986.

BRASIL. Constituição Federal de 1988. Brasília: Senado Federal, 1988. Disponível em: http://www.planalto.gov.br/ccivil_03/ constituicao/constituicaocompilado.htm. Acesso em: 24 jan. 2020.

BRASIL. Decreto-Lei no 5.452, de 10 de maio de 1943. Aprova a Consolidação das Leis do Trabalho. In: Diário Oficial da República Federativa do Brasil. Brasília, DF, 8. ago. 1943. Disponível em: http://www.planalto.gov.br/ccivil_03/decreto-lei/Del5452. htm. Acesso em: 24 jan. 2020.

BRASIL. Lei № 13.352, de 27 de outubro de 2016. Altera a Lei № 12.592, de 18 de janeiro de 2012, para dispor sobre o contrato de parceria entre os profissionais que exercem as atividades e Cabelereiros, Barbeiro, Esteticista, Manicure, Pedicure, Depilador e Maquiador e pessoas jurídicas registradas como salão de beleza. In: Diário Oficial da República Federativa do Brasil. Brasília, DF, 28. out. 2016. Disponível em: http://www.planalto.gov. br/ccivil_03/_Ato2015-2018/2016/Lei/L13352.htm. Acesso em: 24 jan. 2020.

BRASIL. Lei № 13.467, de 13 de julho de 2017. Altera a Consolidação das Leis do Trabalho (CLT), aprovada pelo Decreto-Lei no 5.452 , de 1 o de maio de 1943, e as Leis $\mathrm{n}$ 으.019, de 3 de janeiro de 1974, 8.036, de 11 de maio de 1990, e 8.212, de 24 de julho de 1991, a fim de adequar a legislação às novas relações de trabalho. In: Diário Oficial da República Federativa do Brasil. Brasília, DF, 14. jul. 2017. Disponível em: http://www.planalto.gov.br/ccivil_03/_ato2015-2018/2017/lei//13467.htm. Acesso em: 24 jan. 2020.

BRASIL. Lei no 99/2003, de 27 de agosto de 2003. Aprova o Código do Trabalho. In: Diário Oficial da República Federativa do Brasil. Brasília, DF, 27. ago. 2003. Disponível em: https://dre.pt/pesquisa/-/search/632906/details/normal?q=Lei+n.o\%20 99\%2F2003\%2C\%20 de+27+de+agosto. Acesso em: 24 jan. 2020.

CASTELLS, M. A galáxia da internet. Reflexões sobre a internet, os negócios e a sociedade. Tradução Maria Luiza X de A. Borges. Rio de Janeiro: Zahar, 2003.

CASTELLS, M. O poder da comunicação. Portugal; Lisboa: Fundação Calouste Gulbenkian, 2013.

DEJOURS, C. A banalização da injustiça social. Tradução Luiz Alberto Monjardim. 7. ed. 7. reimpr. Rio de Janeiro: FGV, 2007.

DONEDA, D. Da privacidade à proteção de dados pessoais. Rio de Janeiro: Renovar, 2006.

DUPAS, G. Ética e poder na sociedade de informação. De como a autonomia das novas tecnologias obriga a rever o mito do progresso. 2. ed. São Paulo: Unesp, 2000.

DUSSEL, E. A produção teórica de Marx. Um comentário aos Grundrisse. Tradução José Paulo Netto. São Paulo: Expressão Popular, 2012.

ENGELS, F. A situação da classe trabalhadora na Inglaterra. Tradução B. A. Achuman. São Paulo: Boitempo, 2010.

FONTES, V. Capitalismo em tempos de uberização: do emprego ao trabalho. In: Marx e o Marxismo. Rio de Janeiro, vol. 5, n. 8, p. 45-67, jan./jun. 2017. Disponível em: http://webcache .Google usercontent.com/search?q=cache:XfO_LXwSOpoJ:www. niepmarx.blog.br/revistado niep/index.php/MM/article/view/220/177+\&cd=2\&hl=ptBR\&ct=clnk\&gl=es\&client=safari. Acesso em: 24 jan. 2020.

GARCIA, M.; MARTINS, L. Direito da informática. 2. ed. ref. e actual. Coimbra: Almedina, 2006.

GOLDMANN, L. Dialética e cultura. Tradução Luiz F. Cardoso, Carlos N. Coutinho e Giseh V. Konder. 2. ed. Rio de Janeiro: Paz e Terra, 1979.

GONÇALVEZ, M. E. Direito da informação. Novos direitos e novas formas de regulação na sociedade de informação. Portugal, Porto: Almedina, 2003.

GRASSELLI, O. O direito derivado da tecnologia. Circunstâncias coletivas e individuais no Direito do Trabalho. São Paulo: LTr, 2010.

GRASSELLI, O. M. Internet, correio eletrônico e intimidade do trabalhador. São Paulo: LTr, 2011.

KUMAR, K. Da sociedade pós-industrial à pós-moderna. Novas teorias sobre o mundo contemporâneo. Tradução Ruy Jungmann e Carlos Alberto Medeiros. 2. ed. Rio de Janeiro: Jorge Zahar, 2006.

LASCH, S. Crítica de la información. Buenos Aires: Amorrortu, 2005.

LEONARDI, M. Tutela e privacidade na internet. São Paulo: Saraiva, 2012.

LÉVY, P. A conexão planetária. O mercado, o ciberespaço, a consciência. Tradução Maria Lúcia Homem e Ronaldo Entler. São Paulo: 34, 2001.

LIMA, F. M. M. D.; LIMA, F. P. R. M. Reforma trabalhista: entenda ponto a ponto. São Paulo: LTr, 2017.

LOJKINE, J. A revolução informacional. Tradução José Paulo Netto. 3. ed. São Paulo: Cortez, 2002.

MARX, K. Formações econômicas pré-capitalistas. Tradução João Maia. 7. ed. São Paulo: Paz e Terra, 2011.

MARX, K. O capital: crítica da economia política: Livro I: o processo de produção do capital. Tradução Rubens Enderle. São Paulo: Boitempo, 2013. 
NAVARRO, V. L.; LOURENÇO, E. Â. D. S. (org.). Avesso do trabalho III: saúde do trabalhador e questões contemporâneas. São Paulo: Outras Expressões, 2013.

NISSENBAUM, H. Privacidad amenazada. Tecnología, política y la integridad de la vida social. México: Oceano, 2011.

PÉREZ LUÑO, A. H. Internet y los derechos humanos. In: Derecho y conocimiento. Facultad de Derecho. Universidad de Huelva, v. 2, p. 101-121. ISSN 1578-8202. Disponível em: http://webcache.googleusercontent.com/search?q=cache:Tvoz Sjhf1yUJ:rabida.uhu.es /dspace/bitstream/handle/10272/2550/b15616630.pdf\%3Fsequence\%3D1+\&cd=1\&hl=pt-BR\&ct=clnk\&gl=es\&client=safari. Acesso em: 24 jan. 2020.

PÉREZ LUÑO, A. H. Internet y los derechos humanos. In: Derecho y conocimiento. Facultad de Derecho. Universidad de Huelva, v. 2, 2002, p. 101-121. ISSN 1578-8202. Disponível em: http://webcache.googleusercontent.com/search?q=cache:Tvoz Sjhf1yUJ:ra-bida.uhu.es/dspace/bitstream/handle/10272/2550/b15616630.pdf\%3Fsequence\%3D1+\&cd=1\&hl=pt-BR\&ct= clnk\&gl=es\&cli-ent=safari. Acesso em: 24 jan. 2020.

PINHEIRO, P. P. Direito digital. 5. ed. rev. e atual. e ampl. São Paulo: Saraiva, 2013.

PINTO, G. A. A organização do trabalho no século 20. Taylorismo, Fordismo e Toyotismo. 2. ed. São Paulo: Expressão Popular, 2010.

POLANYI, K. A grande transformação: as origens da nossa época. 5. ed. Tradução de Fanny Wrobel. Rio de Janeiro: Campus, 2000.

REDORTA, J. Cómo analizar los conflictos. Barcelona: Ediciones Paidós Ibérica, 2009.

RIFKIN, J. A era do acesso. Transição de mercados convencionais para networks e o nascimento de uma nova economia. Tradução Lucia G. L. Rosa. São Paulo: Makron Books, 2001.

ROSSO, S. D. Mais trabalho! A intensificação do labor na sociedade contemporânea. São Paulo: Boitempo, 2007.

ROSSO, S. D. O ardil da flexibilidade. Os trabalhadores e a teoria do valor. São Paulo: Boitempo, 2017.

VAIDHYANATHAN, S. A gloogleilização de tudo. (E por que devemos nos preocupar). Tradução Jeferson Luiz Camargo. São Paulo: Cultrix, 2011.

VENCO, S. Uberização do trabalho: um fenômeno do tipo novo entre os docentes de São Paulo, Brasil? In: Cadernos de Saúde Pública, Rio de Janeiro, v. 35, p. 1-16, maio 2019. Disponível em: http://www.scielo.br/scielo.php?script=sci_arttext\&pid=S0102-311X20190 00503003. Acesso em: 24 jan. 2020. 